\title{
An Interview with Elizabeth Grosz: Geopower, Inhumanism and the Biopolitical
}

Theory, Culture \& Society (2017) Special Issue 'Geosocial Formations and the Anthropocene' 34 (2-3): pp 129-146.

\section{Elizabeth Grosz}

Kathryn Yusoff

Nigel Clark

Elizabeth Grosz, Jean Fox O'Barr Professor in Gender, Sexuality and Feminist Studies at Duke University, has played a pivotal role in changing expectations about what feminist philosophy can do and how it should be done. Alongside, and often in a productive friction with, some other notable feminist philosophers (see Colebrook, 2017, Hird, 2017 and Povinelli, Coleman \& Yusoff, 2017), Grosz has insisted on nothing short of cosmological limits for feminism, rather than seeing feminist modes of inquiry as constrained by current formations. To this end, her work has consistently engaged with the 'outside' of politics, located in the forces and the temporalities of the cosmos. In conversation with Foucault and Deleuze (who were in turn engaged with Maurice Blanchot), Grosz's work is attentive to the ways in which the forces of the universe organize the very possibilities of immanence in given structures, and to the way these experiences of the outside (Foucault, 1990: 15) press on and deform - as well as incite - social, sexual and political relations (Grosz, 2008). What she takes from the cosmic 'outside' is how these inhuman forces modify social relations, where the social is always lived in relation to and in defiance of that celestial storm.

Grosz has consistently argued that we need to recognize that universes (to come) are 'possibles' of a present anterior that need to be welcomed in all their difference. The welcoming of the new is not just a moment of hospitality to enlarge the possibilities of the universe and make it otherwise (although this is undoubtedly its creative and sexual charge), it is also a crucial movement toward more just and fulfilling feminist futures that are not curtailed by the power dynamics of their pasts. In this political alignment between feminist futures and the earth, Grosz (2008, 2011) pushes beyond the disciplinary limitations of the earth and biological sciences while identifying the potential of those resources to be used differently. 
The productive engine of difference is at the heart of this realignment of the sciences and the claim for a cosmological perspectivism for feminism. As Grosz argues, difference is the generative force of the world that enacts materiality: 'The movement of difference that marks the very energies of existence before and beyond any lived or imputed identity. It is the inhuman work of difference ... difference stretches, transforms, and opens up any identity to its provisional vicissitudes' (Grosz, 2011: 91). The challenge of differentiating from patriarchal pasts (that has been an aspect of Grosz's earlier psychoanalytical work on Lacan, Laplanche and Irigaray) reappears in a more recent engagement with the earth and its forces, and in the challenge of making feminist futures uncontained by the pasts that have sought to contain and marshal those forces to particular oppressive ends. With discussions of materialism (2005), the framing of the earth (2008), and geopower (2011), Grosz has pushed towards a future that dares to claim for feminist theory - as one of her chapters is entitled - 'Dreams for New Knowledge' (2001: 74). The kind of feminism that this delivers is one that is open to the future by way of openness to the forces of the world that are always already excessive. This attachment to an expansive field of engagement for feminism as both a mode of philosophical inquiry and an organization of material explication is deeply hopeful in its rendering of possibles that 'act up' and challenge the presumed given-ness of place.

In keeping with the space and tenor of the unfolding of what Deleuze and Grosz each call chaos, Grosz's approach both explicitly addresses patriarchal forms and allows an excess to enter the frame that exceeds that address and takes us elsewhere into the possibility of new formations. In parallel to anti-racist and decolonizing literatures, resistance is pushed through the recognition and partaking of new material relations with and in the earth (see Last, 2017, this issue).

In the transformation of materials from the past into resources for the future, Grosz's work is deeply geophilosophical. It attends to both the virtuality of earth forces and the modes of realization of territory as an ongoing engagement with terrestrial forces; territory is a 'provisional stability' (2008: 70), and one that mobilizes sensations and affects. Grosz argues that the recognition of the two orders of the inhuman the pre-individual and the impersonal - provides a freedom for the subject 'who understands that culture and history have an outside, are framed and given position, only through the orders of difference that structure the material world' (2011: 97). In this sense, Grosz resists the easy political gratification of over-determined accounts of earth forces, without losing any of the contours of how power, sex, race, oppression, biology and futurity function through those forces to underpin geopolitical and subject formations (2011). In the recognition of difference as the undoing of stability and consistency in subjects, Grosz sets out to understand the regimes of teaming acts that constitute the formations called patriarchy, racism, heteronormativity as a multiplicity of acts and bodily positions with a shared patterning but not a latent order. She suggests that we consider these acts as what we are and what we make 'that constitute the conditions under which other kinds of inventions, other kinds of acts, become possible’ (2011: 98). 
If one of Grosz's recent geophilosophical contributions is thinking through power and its movement through the earth into art and politics (through her critical reading of Darwin, Bergson and Deleuze), the other is her sustained attention to the role of the inhuman in the humanities. In relation to the outside, inhumanism is crucial in the way it both provokes new geosocial formations into being and modifies the claims to autonomy within any such relation. This relation to the extant energy of inhuman forces puts pressure on, but also creates possibility in, material and political life; life that is historically contingent but cosmically determined in ways that produce a divergence towards an excess or overcoming of those same material and political conditions. These inhuman forces situate desire by way of framing an incomprehensible universe (as in art that brings shreds of chaos into sensation) and as a means of actualizing that virtuality for the creation of new forms of becoming and differentiation. The capitalization on the forces of the universe - or geopower, as Grosz puts it (2011) - has the potential to be harnessed as pleasure and as capital accumulation. But while these geopowers might subtend political potentials, they are never reducible to them - and so always remain radically open to transformation. Geopowers might well be channelled in capitalism, but the organization of power belongs to the earth - even as the earth is itself is opened to new forms of becoming through the reorganization of its forces. As Bergson writes: 'the universe endures', and in her rejoinder Grosz argues: 'becoming infects not only beings in/as duration, but the world itself (2008: 16). What is important in this approach is that excess is not dismembered from its potentials, and this virtuality of the cosmos remains as a form of commons for all life, rather than being reduced to the limits of its utility in social worlds (2008: 67) or fully repatriated to the side of consciousness. And in this regard, the act of framing chaos is a way to make 'sensation live, each evokes a people and an earth to come, each summons up and pays homage to imperceptible cosmic forces, each participates in the (political) overcoming of the present and helps bring a new rich, and resonating future into being' (Grosz, 2008: 103).

Nigel Clark and Kathryn Yusoff: There are still very few theorists in the humanities and the social sciences who write about fully inhuman or geologic or inorganic forces, let alone writing through or with these forces. On the face of it, an interest in sexed and gendered human or even nonhuman bodies does not seem the obvious place to start in order to arrive at the definitively unsexed, non-sensual and undesirous domains of the geologic. Could you tell us something about the kind of questions, provocations or attractions that drew you into engagement with the 'geo'?

Elizabeth Grosz: Well, in a way, the geological/geographic order is the most tangible and concrete condition for all forms of life, and indeed, for the existence of all terrestrial objects. It is often left out of consideration in addressing philosophical and political questions, elided or considered inert, non-living. For me, it was, to begin with, Foucault's writings on questions of space and geography that made explicit not only the historical and genealogical emergence of specific forms of power, but also its geographical conditions. We have tended to imbue life with history, with 
temporal progress, but we have largely left unthought its geological context. The 'geo' is an inversion of the 'ego'! It leads us to understand what may have an agency or force on forms of life and on material objects: the earth itself, while 'unliving' as chemical elements and forces, can be understood as having a kind of life of its own when it is understood as a system of order and organization that is continually changing, never fully stable, dynamic. If dynamism is a quality of the earth as a whole, if the very framework of life, its literal grounds, are never fully stable - or rather, are functionally metastable - then all our conceptions of life, and the human, acquire a kind of unstable, potentially transforming ground. To see life as coming from the earth and its forces - gravitational, magnetic, electrical and so on - is perhaps the most powerful and direct way to destabilize our concepts of identity and agency. If the earth is riven by agents, acts and events - if it is not inert and passive - then life cannot be understood to master itself; life must look outside itself to attain the possibility of continuing itself and knowing itself.

$\mathrm{NC}$ and KY: Unlike some of the writings on life that stress a certain amount of incessant activity, geologists and other evolutionary scientists (for example, Stephen Jay Gould's theory of punctuated equilibrium) have tended to emphasize the role of stasis, of nothing much happening for vast stretches of geologic time, which is punctuated by the often abrupt and catastrophic events that form the geologic record. So while the thin fleshy biosphere might always be in the rapture of dynamism, the geological feedstock has tended to be thought of as a metastable 'foundation' that is only subject to infrequent dynamism. Given your understanding of life as provoked by a lack of fit between the organism and the world, how would you characterize this temporal 'lack of fit' between the organic and inorganic? Or, to put it another way, how does geology provoke life as a consequence of this temporal/durational difference? That is, how can we see life both 'coming from' but also going away from the earth and its forces?

EG: In my understanding, there is no equilibrium in real environments but at best only in small fields where the potential for change is already exhausted. If there is a relative stabilization at the geological level which in any case is not true of specific locations, which are always subjected to change - it is only a question of level: the geological is always moving, always transforming, even if it is not always impacted by catastrophic events (that is, events catastrophic to particular forms of life rather than to any geological formation), is continuously marked by the events that occur below and near the surface of the earth. It is a question of scale. On the level of vast geologic periods - eras lasting billions of years - there may be intermittent or punctuated catastrophes (these are very far from equilibrium), but at the level of, say, the 'lived' time of a geological element - the time it takes, for example, for a stalagmite to form - there is continuous, unpunctuated (even if interrupted and transformed) change. As metastable, the geologic cannot function as foundation or beginning without it being rife with disparities, without it being an order of endless, intimate contrary forces which generate the necessity for change. The geologic provokes life to the extent that it is metastable, to the extent that is in a continual process of resolving differences 
of flow between different inorganic forces - electrico-magnetic, chemical and so on - that are also the raw materials and conditions for life's emergence from an environment. The geologic is the condition for the distinction between life and a milieu, insofar as life itself is not a given identity but relies on the emergence of a prior mode of chemical (and geologic) organization. I am not sure that this is merely a temporal process, without it also being a spatial process. We can see life as both coming and going away from the earth and its forces. It is precisely this disparation between these two forces that generates problems whose resolutions move from the earth (a disparation that appears as well in the simultaneous functioning of past and future on the present). To the extent that it emerges, in evolutionary terms, from the earth, life is always from the earth and remains affected by the earth and its forces even as it generates a kind of higher order 'minerality', a different geological circulation. But, as you suggest, life is a departure from the earth, or at least from what is already contained in it, insofar as life elaborates from this metastability what has never happened before, what cannot be predicted in advance, and what can be invented. The earth is perhaps not the only geologic and cosmological system that can contain life; life on earth directs itself to the stars, little by little, as it too comes from the stars.

NC and KY: You recently used the notion of 'geopower' as a way of characterizing the geological, inhuman and preindividuated forces that subtend and provoke organic life. For many readers, the obvious counterpart, or perhaps counterpoint, to geopower will be Foucault's concept of biopower - which is to say to a specific set of technologies or strategies for managing bodies. For many social scientists, in particular, Foucauldian notions of biopower and the biopolitical have been taken to imply that it is no longer possible to speak of biology in any way other than as an object of human political ordering. All of which seems very different from what your concept of geopower seems to be setting out to do. Could you say more about the relationship between biopower and geopower?

EG: I don't think I introduced the concept of geopower at all! I seem to recall it from Foucault's work, especially his 'Questions on Geography' (Foucault, 1980), which was for me a very important text insofar as it introduced the idea that geography is itself the object of power relations. I don't think it is analogous to his concept of biopower, which addresses precisely the social regulation of bodies and their actions, their positioning in a grid through which power can regulate and normalize the behaviour of bodies. For him, biopower regulates a body from the outside: it is a body, or many bodies, insofar as they intersect with and are transformed by institutions and their requirements. One could use a different concept of biopower than the one Foucault developed, if one wishes to produce a greater symmetry between biopower and geopower than he does: this would require biopower to be considered not only as a body insofar as it is regulated by historically specific forms of power, but the powers of a body, in principle unknowable to the extent that we do not know what a body can do. In other words, biopower could be understood as the powers that operate in and through living bodies, the powers 
of a body that can be harnessed for particular forms of action and passion.

This would draw it closer to his own concept of geopower, the powers of the earth that may enable life to survive. Rather than concede geopower as the power that humans can extract from or hold over the geological, he sees geopower as the forces of the earth. In many ways, it is probably Deleuze and Guattari - and their depersonalized (and some say depoliticized) conception of power as forces that run through things - who have been responsible for a more geological focus, in some kind of alliance with Foucault, who are philosophers who have enabled us to address not only space but, above all, the earth as the coagulation of various forces, organized by the plane of planes, as constructions by life that address the living forces of the earth. Deleuze and Guattari have insisted on the irreducibility of the geological, not only as a stratified diagram of the real, but also as the condition for the excess of energy beyond identity that marks every living thing with the milieus or environments that make them possible and link them together.

In brief, I agree that Foucault's concept of biopower is very different from his (and Deleuze and Guattari's) concept of geopower. Biopower is, for Foucault, the power over life that regulates it from outside; but geopower has no outside, no 'place' or 'time' before or beyond it: it is the force, the forces, of the earth itself: forces which we as technical humans have tried to organize, render consistent and predictable, but which we can never fully accomplish insofar as the earth remains the literal ground and condition for every human, and non-human, action.

NC and KY: Historically, the inhuman has been posited as a condition that was understood to be against life (Lyotard, 1991) or as a form of bare life rendered through a deadly exercise of biopower. How might the inhuman be rethought as a stratified condition that both supplements and subtends biopolitics? What kind of shift in genealogy does this represent for the conceptualization of the body politic of the human?

EG: If the inhuman is not understood as against the human, its opposite or overcoming, but rather both the preconditions and the excess within the human, if we understand what is creative and inventive in the human as something impersonal, with forces we summon up rather than control, then it is a line that runs through human actions. In fact, it may be part of the explanation for the cultural necessity of biopolitical regulation: there is something in humans (and other living beings) that is beyond conscious control and social regulation. The increasingly microscopic interventions of biopower take as their object smaller and smaller forces and processes of the body as something to be mastered while leaving inadequately addressed the body's inhuman even quantum forces. Biopower requires as its other precisely the inhuman, which it aims to make an object of regulation. Or put in other words, it is the inhuman in the human that resists biopolitics and perhaps requires some form of it. The inhuman within the human, as resistance, is the creative force that enables (some) humans to transform their conditions of existence, to make, create, invent. Moreover, this inhuman is the gel of a human collectivity that is perhaps best understood through art, which musters both the elements from the earth and from the inhuman effects of the human. 
NC and KY: In some of the recent - if still rare - philosophical engagements with minerality, the geologic or the inorganic, it seems as though what is considered most interesting is the capacity to sooner or later come to life, or at least to self-organize into new and interesting forms. But if we survey all the matter in the universe - or even in the interior bulk of the earth - life is actually rather rare. Indeed, we might even describe the emergence of life on earth as a singular event. As geologist Jan Zalasiewicz reminds us, 'minerals can remain in a metastable state virtually forever, if nothing catalyses their breakdown' (2008: 20). In this regard, are we still largely engaging with the geologic in terms that we can recognize and identify with, rather than in itself? Philosophically, politically, or aesthetically speaking, is there any traction in the physicochemical stratum when it endures or obdures in states that are neither self-activating nor activated by the living?

EG: There are two different questions here, I think. First, a question about the ontological or ontogenetic distinction between life and inorganic matter; and second, an epistemological question about how the geologic can be known in itself. Ontologically, I don't think that the inorganic as such can come to life - nor do I think that life is a rare improbability. On the contrary, it seems to me that if we follow current geological and cosmological research, such as that of Lee Smolin, and philosophies, such as Deleuze's or that of Gilbert Simondon that attempt to address them, there is a gap between matter and life, but it is a gap of degrees rather than, as Bergson argued, a difference in kind. There are gradations between, say, the ontogenesis of a crystal, the processes of metastability that differentiate and co-ordinate the relation between two material forms, the germ-seed and the supersaturated liquid from which it forms itself, and the genesis of a living individual: indeed living beings require and continue the geological movements of minerals, salts and other geological forces by which their movements are internally regulated, even as the geologic emerges at a different and higher level of organization and information in the living (or dead) body. The geologic always abides, in Simondon's terms, as the preindividual and transindividual which each individual carries with it both internally, as part of its self-constitution, and externally, as (partial-)milieu. So in one sense we, as living beings, have a partial but direct access to our own minerality, if I can call it that, to the extent that the mineral is a condition of life; on the other hand, the geologic order is not simply socially constructed, not simply a projection, but a series of abiding and changing forces that we do not control, let alone adequately understand, that pose questions to us about our own lives, and the 'life' or the mode of existence of the mineral. I think that we need to see the physico-chemical stratum as both endless resource for all future individuations, inorganic or organic, and as the lowest order of material organization that persists and remains as a resource for ever-elaborating orders of complexity. I don't think that the geologic order is socially constructed, though of course our knowledge of it is socially mediated.

NC and KY: What obliges us towards the inhuman or, to put it another 
way, what obligations are already posed as deriving from the inhuman? How do these obligations towards geology change the 'nature' of a biopolitical body?

EG: I don't know if I would use the term 'obligation' or 'obliges' here. We are immersed in inhuman forces both outside us and within us, whether we know it or not. To be obligated, to feel as if we must be drawn to new perspectives or new forms of biopolitics, is an ethical affect. If we are inhuman, how are we to understand ourselves, the nature around and within us, and politics that positions us? I don't know. But one thing that may be relevant is that the inhuman, as resistance, is always to some extent and in some way beyond biopolitics. It is important to seek out these sites of resistance at whatever level and manner they occur. These sites are those that must be left aside in the rational and economic management of 'things'. But there is something left over that remains resistant, that wants what it wants, before and beyond biopower.

NC and KY: We have found your discussion of art as an extraction and harnessing of the dynamic forces of the earth very useful for helping to understand some of the pyrotechnical arts that emerged in - and helped create - the cities of antiquity. It is interesting to consider that crucial developments in the use of heat to transform 'earthy materials' seem to have occurred at a time of late Pleistocene-early Holocene rapid sea level rise - an event which earth scientists have also linked to an escalation in seismic and volcanic activity. This in turn sparks some questions and speculations about what kinds of 'artistic' interventions into the chaos now being triggered by human-induced climate change we might yet witness. There is a growing body of art 'about' climate change, but perhaps we have yet to see new genres or practices that tap into and work with the shifting forces of the contemporary earth. Without any expectation of foretelling art-to-come (!), we are interested in your thoughts about what we might look for, hope for, dream about, with regards to new kinds of material practice for an era of intensifying geophysical turbulence.

EG: Wow, this is a big question, on a time-scale that is difficult for me to contemplate! If Simondon's work is relevant in this context, it is because he understands that crises, problems about how to exist, to bring oneself into being and to acquire powers of acting, whether at the inorganic or organic levels, always involve creation or invention, which never comes easily, and often emerges under the strangest and least conducive conditions (such as the art that was produced in concentration camps and refugee camps), sometimes without the slightest consciousness. Sometimes just a small shift in position enables something to be released from chaotic forces and be harnessed for production, whether artistic or technical. For Simondon, there are two possible ways of addressing crises of the earth - technologies and art (and at their best, technology as art), each of which innovate, in their own ways and with their own temporalities. If we focus on art, we can see that art has, over the last 200 years, become less a representation of something that pre-exists art than the exploration of a process or perhaps, even, events that have more and more to do with the material conditions and limits of art. I think that, as 
one of the current political crises of the present, climate change, or its particular events - storms, rising tides, volcanic and seismic activity - it is inevitable that art has and will come to address this in its own terms. We must remember that art aims, at the least, at a provisional consistency in its harnessing and framing of natural and biological impulses and affects, and for this it needs a way of addressing those parts of the earth it requires. It needs to invent a way, or many, of addressing what of a storm, or any short-term event, it can make of itself.

NC and KY: Recent social thought is pervaded by relatively 'horizontal' models of actual and potential relating, as in networks, interconnectivities, rhizomes, and topologies (that most often set out from 2-D space).

Such reluctance to consider more stratified subtending relations now seems somewhat out of proportion to threats of foundational or deterministic thinking. By contrast, in your work - especially in the context of the inhuman, the geologic, the inorganic - there appears to us an unabashed embrace of subtending potentialities and relations. Variously drawing on Deleuze and Guattari's notion of stratification, Derrida's inheritance, or Nietzsche's " that which was" is the name of the stone he cannot move' (Grosz, 2004: 150), there is a strong sense in your work of domains that are at once out of reach of the political, but also the very condition of human politics. Why do you think there is so much reluctance in contemporary critical thought to make ontological claims that are not immediately and directly accessible to politicization?

EG: It is understandable that there is a reluctance to make ontological claims in contemporary philosophy. Ontology, primarily understood in terms of metaphysics, has been used precisely as a way of avoiding the empirical: by the time Bergson was awarded his Nobel Prize in literature, his work was subjected to quite vicious criticism from Bertrand Russell and other philosophers in the analytic tradition who understood philosophy on the model of logic, as a precise analysis of statements convertible into symbols. For at least 50 years, the identification of the metaphysical with the physical overcame the power of ontology. To put it too vaguely, science, and especially mathematics, provided models that replaced the idea of the real with that of logical order. Epistemology overshadowed ontology, even though every epistemological position involves ontological assumptions. Spinoza, Nietzsche, and Bergson, Deleuze's intellectual touchstones, each elaborate, in very different ways, an order (or many) in the universe that was at best only partially addressed through the sciences, and only accessible to knowledge through technological mediation. What each of them affirmed was an ontology that assumed that there is only one world, a world accessible to science but also addressed by and always framing living beings in their social, political, ethical and aesthetic relations.

Spinoza begins the Ethics from the top-down, from the most abstract and necessary assumptions, working to an understanding of the real relations between humans, between ideas, and the order of the universe; Nietzsche understands that everything, whether living or inert, whether microscopic or cosmological, is driven from inside by a will to power that not only explains the orders addressed by physics and chemistry but also history and politics; and Bergson understands that, if we know the world's 
orderly causal relations through intelligence, an organ furnished by evolution to maximize actions, it must be supplemented by intuition, the evolutionary heir of instinct, an understanding of the place of the singular within the whole of existence, the shared life of subject and object. Each one, in other words - and this is in part what attracted Deleuze to these philosophers - develops a way of connecting a larger, natural order to the smaller order of human social and collective life non-reductively. Each links an understanding of the orders of existence with an understanding of the political and social orders that are subjected to historical upheavals. Each sees a fundamental link between the distance, the framework or perspective provided by ontological analysis, and the near-focus of social and political relations, not by analogy (or if it is analogy, as in the case of Simondon, it is a reticulated and amplifying analogy) but directly. There is no reason that we cannot analyse social, political and cultural life through the same lens as we view the orders of the real - as long as we understand there must be, as you describe it, different levels or orders of the growing complexity and autonomy of the processes of existence. If becomings, natural and social, are (self-)regulated, this kind of regulation cannot be different in kind to that of the universe itself.

I understand, however, that those committed to a more direct form of political action or activism, whether in feminist, queer, postcolonial or global terms, see the connection between philosophical theory and political practice as more and more tenuous and abstract. This is true.

Moreover, it is true that political activism has itself always involved ontological assumptions, which are sometimes, perhaps, philosophically irrelevant but function as modes of mobilization. It seems to me, as a feminist theorist, that feminist theory does not, as a whole, need to address questions of ontology: this depends on one's particular project. But unless the bigger questions about how to think about the earth, the cosmos, and time and history, are also asked, we will remain stuck in activisms that are merely reactive - against patriarchy, against sexual normalization, against the colonial or the global - rather than fully creative and capable of inventing new ways of collective life.

NC and KY: You have suggested that art carves out a relatively safe corner of the earth's chaos in which to perform experiments. One of the key differences between the spheres of politics and art - at least in a conventional modern framing - is that politics involves justifying our actions or inaction to others (i.e. giving reasons for our decisions), whereas it is presumed that artistic interventions can to some degree speak or act for themselves. So we are wondering what your approach does to complicate or trouble these differences. If a politics worthy of the name calls for trials and experiments whose outcomes cannot be anticipated, is the emphasis on the providing of reasons or giving an account of oneself over-rated? Or alternatively, if art has the capacity to recompose social formations in potentially momentous ways, are we perhaps not being demanding enough of its ethical and political responsibilities?

EG: I think that art and politics do function quite differently, although there is no reason that each mode of practice cannot borrow from or help to develop the other. But the most fundamental difference is that art is 
very rarely, with the exception of film and performance arts, a collective process (though of course it is capable of collective creation - it more commonly is marketed rather than produced collectively). Art is possible in a relation between a single individual and a small part of the earth. Politics, by contrast, is always collective, always social, completely ineffective if it relies on individuals alone. What both art and politics can share, though this is increasingly difficult in a political order in which the domination of politics occurs through the financial intervention of restabilizing orders (such as the interests of particular industries and the operation of lobby groups), is that at their best, they are fundamentally experimental, open-ended, without a clear-cut goal, but modes of exploration of different possible (or virtual) orders.

We have, in the last couple of years, witnessed a series of extraordinary political events that were relatively unplanned, that aimed to invent new forms of coexistence and that undertook experimental modes of organization - from the recent revolutions and the 'Occupy' movement to Pussy Riot. The latter two political events remain closer to art than to conventionally conceived politics. Politics, like art, requires the capacity to freshly address and mobilize something - a movement of coordinated people, a movement of qualities - so each requires an energetic revitalization to remain relevant. I myself have found that the old leftist forms of politics - Marxist-oriented class politics, the identity bases of feminism, LGBTQ and post-colonialism, for example - do not seem able to mobilize a new constituency as they once did. This does not mean the end of such political struggles, but it may mean rethinking, or experimenting with, new goals, new struggles, new questions, thinking more 'artistically'. And art practices, often regarded merely as forms of self expression, are themselves, at least in part, political explorations of the materials and contexts of art, forms of self-questioning of the field itself. I am reluctant to speak of the ethical or political responsibilities of art that are somehow outside art: art doesn't need to be responsible for ethics or politics to be able to engage with ethics or politics. But ethics and politics are different, if not unrelated, practices that art may address but which have their own methods, tactics and goals. These practices - aesthetic practices (creation and reception), political practices (collective or group interests insofar as they struggle with each other), and ethical practices (the creation of ways to live, the invention of values by which to live) - can align, though always in ad hoc or unpredictable ways.

NC and KY: You have spoken of politics as 'an invention, a labour of fabrication, of experimentation', more linked to artistic production than to more conventional political concerns of planning, policy-making and such (Grosz, 2005: 260). Contemporary critical thought around the political still seems much more wedded to notions of recognition, fair and open communication, and continuous dialogue than it does to hands-on experimentation with the physical stuff of the world. Even when the more-than-human 'composition' of worlds is at stake, it appears that we are being called on to prioritize processes of discussion and the seeking of consensus. Occasionally in times of crisis, such as during Hurricane Katrina, authorities have been criticized, among other things, for sticking to the regulations and not improvising boldly enough. More often, however, the 'state of exception' is invoked, and 
critical thinkers offer dire warnings about any intervention that bypasses due political process. Perhaps this is most pronounced today in the deep suspicion that surrounds any consideration of 'geoengineering' responses to the climate predicament. Is there a tension here? Do you see a more open-ended and experimental politics as necessarily subsumed in collective decision-making processes, or might there be occasions where it is conceivable to lead with more practical interventions? To put it another way, might we not see in the ascendance of certain modes of geo-technics the beginnings of an exploration of a space of possibilities that critical political practices have evacuated or failed to claim?

EG: You are right to suggest that many, if not most, forms of contemporary critical thought are committed to the notion that it is classes or groups of individuals, those who share elements of an 'identity', that constitute the various competing political interests that struggle within the social order. They also tend to share the belief that recognition of minoritarian identities as 'equal' to all others by the social majority is a condition of a successful struggle. Politics is, in such a view, the struggle for 'others' of all kinds, including in some cases animals, to acquire the recognition of society as proper persons and equal members of civil society. But there has always been a strand of experimentation and the enjoyment of upheaval even within the most rigorous and sincere forms of recognized political struggle, an anti-consensual, autonomy-seeking mode of affirmation (perhaps it is Nietzsche who pioneered such a politics, a politics of the wayward individual outside of organized groups and never seeking recognition!), from Emma Goldman and the anarchists to radical feminism and to the work of Deleuze and Guattari. Part of the problem is that there are two tendencies within political struggle that should not be mediated - a desire for a place in collective life, and a desire for an autonomous, that is, self-regulated life - that is, between equality and autonomy. Revolutionary upheavals rarely occur collectively (though there are exceptions, such as the 'Arab Spring' and 'Occupy', whose long-term effects are not yet clear): but it is up to collective practices to bring revolutions into existence. So I really want to resist the regulation of experimentation and invention by collective agreement; but equally I want to resist the regulation of collective practices such as the work of the sciences, of artists, of 'theorists', of workers - by experimentation.

If we want to use the example of geoengineering, an excellent example in this context, the practice, and the technical ensembles that are required to undertake large geoengineering projects, it is both true that it is likely that interventions into nature on such a large scale (both financial, geographical and technical) are going to be regulated by the demands of profit and consumerism (this is strikingly clear with the mining of vast regions of Western Australia, say, which do not profit the earth or its local inhabitants and indeed tend to harm them). On the other hand, geoengineering projects have immense potential to reform parts of the earth for different modes of inhabitation - the creation of dams, or architecture, to take the simplest examples - which, while harming some animal life, enhances other forms. Like all forms of technical invention, geoengineering has the potentiality for immense change. But without the careful regulating of competing interests - those of the local and 
more general environment, those of the inhabitants of a region, those flows of energy and minerals that run through a location as well as those of employment and economic production - it is right that we feel fear and anxiety at the likelihood of further destruction of our environment. And it is right for us to be very suspicious when corporations and governments inform us that such vast projects will 'help' a population rather than a small fragment of a population.

$\mathrm{NC}$ and KY: While many of the questions being posed in critical theory take the organization of life and nonlife as a point of departure for a politics of differentiation, could you suggest what other passages of thought and material configuration might the inhuman provoke? How might recognition of the resistance of being or, to put it another way, a way of being that is not always skewed towards the living, be expressed?

EG: The inhuman is a very general concept that seems to really only be able to be pinpointed by explaining what it is not. If the inhuman is the non-human, then it encompasses the non-living, material or natural order, what is before or beyond the human. Then it is not only the material that faces the inhuman, it is also ideality or conceptuality that is inhuman. This ideality, rationality or order is often understood in religious or artistic terms, but it is as much a condition of matter as it is for life. The difference between and connection of materiality to ideality makes clear that the human is always in excess of itself, always moving beyond the human, even in its most characteristic acts. If thinking, inventing, acting, are characteristics of even material forces, then the human is composed of intensities that are themselves not human, or not only human.

I am not sure that I understand what you mean by 'a resistance of being towards the living'. I think, from an earlier question where you suggested the rarity of life, that I don't agree with this. Life seems to me to be possible in many forms which may not be actualized or whose differences we haven't adequately understood. Indeed, as Stephen Jay Gould made clear in his work on the Burgess Shale Formation, many forms of Cambrian life that are utterly unrecognizable as of this earth clearly existed but were subject to massive waves of extinction. Other forms of life replace them, taking advantage of ecological devastation. There is a tendency to life whenever the orders of ideality and materiality emerge, which is to say from the simplest 'particle' or element of matter to the most complex forms of social organization. The self-organizing properties of matter are forms of affinity and boundary, a spark of indeterminacy as Bergson understands it, that condition life and beckon its experimental emergence. This is why it is not only subjects but also objects that require individuation, processes which produce them and enable their relations to form each other. All of matter tends to life in different degrees of openness, and with different forms of ideality.

$\mathrm{NC}$ and KY: If we recognize life's promiscuity in the realm of ecological devastation, could we also not say that life, to a certain degree, is towards 
certain modes of extinction as much as it is towards the flourishing of life? That is, might we recognize a realm of division in life's affiliation that might helpfully (or not!) articulate the 'two lives' - human and inhuman - of life?

EG: Yes, life is, on a cellular level, directed towards extinction (with rare exceptions, such as the self-regenerating hydra); but at the level of the organism, life is directed to the future of life, even in the face of extinction. This may in some small measure explain the irrational resistance to the catastrophic forces of climate change. There are not just 'two lives' we live, human and inhuman, but many, many lives (perhaps even all the gradations between the human and the inhuman by which the human came into existence), each with their own power and force. And there are many deaths. I don't think that life is oriented to extinction: but its fragility and dependence on quite narrow conditions makes it always provisional. The human's future orientation has made the human blind to the supporting conditions, the associated milieus, that it relies on and must support and regenerate.

$\mathrm{NC}$ and KY: Trying to be cognizant of the inhuman raises questions about how to write for/with 'others' when those others are inhuman. What or where is the realm of the inhuman in the context of writing or being written, in modes of inscription, compulsion or obligation?

EG: This is the question, one that is not entirely new. Roger Caillois wanted to talk about stones as if they were subjects, as if they were sentient. Simondon too claims that our being human and social is conditioned on our relations to a natural order and to the technical objects we have produced from our immersion in this order. We have ceaselessly attempted to write for and of objects: it is only recently that we have come to understand more clearly what writings with them, or between them, might involve. It must involve an awareness of our own inhuman connections, both genetic and affective, our own capacity to spill over our human boundaries; but it must also involve a submission to enformed materiality and its particular qualities. We have a model for such an engagement already. It comes from the world of art, and even the artisanal, which does nothing but inscribe the material through the human. Writing needs to come closer to the labour of artistic production if it is to touch objects, and others, the inhuman, in a different way than as speculative passive object of reflection.

NC and KY: Are there any particular ways in which you are interested in how the inhuman gives testimony?

EG: 'Testimony' is too religious a term to suit me. The inhuman gives rise to information, an overflow of information, which is both the movement of certain forces and the possibility of their being known. So I am interested in how we can 'read' the inhuman, however provisionally, whether it is in terms of science, technology, philosophy or art. It does not speak. 
We have to learn how things, processes, events - inhuman forces in their broadest sense - address us without language ever being adequate for the task. We have to invent ways to return to it the knowledge that it imparts to us without anthropomorphism. This is perhaps the current task of the geologic/geographical/political field.

This interview took place in October 2015.

\section{References}

Blanchot, M. Foucault, M. (1990). Foucault Blanchot. New York: Zone Books New York

Foucault, M. (1980) Power/Knowledge: Selected Interviews and other writings, $1972-$ 1977 ed. Colin Gordon. New York: Pantheon Books.

Grosz, E. A. (2011). Becoming Undone. Darwinian Reflections on Life, Politics and Art. Durham, N.C.: Duke University Press.

Grosz, E. A. (2008). Chaos, Territory, Art: Deleuze and the Framing of the Earth. Durham, N.C.: Duke University Press.

Grosz, E. A. (2005). Time Travels: Feminism, Nature and Power__Durham, N.C.: Duke University Press.

Grosz, E. A. (2004). The Nick of time : Politics, Evolution, and the Untimely. Durham, N.C.: Duke University Press.

Grosz, E. A. (1995). Space, Time and Perversion: Essays on the Politics of Bodies. New York: Routledge. 
Grosz, E. A. (2001). Architecture from the Outside: Essays on Virtual and Real Space. Cambridge, Mass. MIT Press.

Grosz, E and Yusoff K. (2014). Ontogenesis and the Ethics of Becoming: an interview with Elizabeth Grosz by Kathryn Yusoff. Environment and Planning D: Society and Space Open Site http://societyandspace.org/2014/05/22/on-ontogenesis-and-theethics-of-becoming/

Zalasiewicz, J. (2008) The Earth After Us. What Legacy Will Humans Leave in the Rocks? (Oxford, New York: Oxford University Press)

Yusoff, K., Grosz, E., Clark, N., Saldanha, A., \& Nash, C. (2012). Geopower: A Panel on Elizabeth Grosz's Chaos, Territory, Art: Deleuze and the Framing of the Earth. Environment and Planning D: Society and Space 30(6), 971-988. 